\title{
PERTUMBUHAN EKONOMI, SEKTOR UNGGULAN DAN KESENJANGAN PADA EMPAT KABUPATEN DI PULAU MADURA
}

\author{
Oleh: \\ Dedi Susanto \\ Mahasiswa Pascasarjana Universitas Gadjah Mada Yogyakarta \\ E-mail/No. Hp: dedy_sus@yahoo.co.id/-
}

\begin{abstract}
The objective of this research was to know economic growth levels, economy patterns, supreme and non-supreme sectors and gaps on each regencies in Madura Island. This research used descriptive quantitative method. According to the analysis' results which had been conducted, it could be concluded that each regencies in Madura Island during the time period 2005 to 2009 the economic growth experienced fluctuation and the pattern of the economy had to be concerned in Sampang regency due to it fell in the relatively left behind criteria. While, for the supreme sectors, they needed to be more improved so that it would be more advanced. The gaps on these four regencies included in medium criteria, yet, the index value needed to be concerned because it tend to keep increase every year.
\end{abstract}

Keywords: economic growth, economic basic sector, and economic gap.

\begin{abstract}
Abstrak
Tujuan penelitian ini adalah untuk mengetahui tingkat pertumbuhan ekonomi, pola perekonomian, sektor unggulan dan bukan unggulan dan kesenjangan pada masing-masing kabupaten di pulau Madura. Penelitian menggunakan metode deskriptif kuantitatif. Menurut hasil analisis yang telah dilakukan, dapat disimpulkan bahwa pada masing-masing kabupaten di pulau Madura selama kurun waktu dari tahun 2005 s/d 2009 pertumbuhan ekonomi mengalami fluktuasi dan pola perekonomian yang harus di perhatikan di kabupaten Sampang karena termasuk dalam kreteria relatif tertinggal, sedangkan untuk sektor unggulan perlu ditingkatkan kembali agar menjadi lebih maju. Kesenjangan di empat kabupaten tersebut masuk dalam kereteria sedang, tetapi nilai Ideks perlu lebih di perhatikan karena tiap tahun terus cendrung meningkatan.
\end{abstract}

Kata kunci: pertumbuhan ekonomi, sektor ekonomi unggulan, kesenjangan ekonomi.

\section{PENDAHULUAN}

\begin{tabular}{lrr}
\multicolumn{2}{c}{ Pembangunan } & nasional \\
merupakan usaha & peningkatan \\
kualitas manusia dan & masyarakat \\
yang & dilaksanakan & secara
\end{tabular}

berkelanjutan berdasarkan pada kemampuan nasional, dengan memanfaatkan kemajuan ilmu pengetahuan dan perkembangan teknologi dan serta harus 
memperhatikan

perkembangan

Pelaksanaannya mengaju pada kepribadian bangsa dan nilai luhur yang universal ditunjukkan untuk mewujudkan kehidupan masyarakat yang berdaulat, keadilan sejahtera, mandiri maju dan kokoh kekuatan moral dan etikanya.

Tujuan pembangunan nasional adalah untuk mewujudkan masyarakat adil dan makmur yang merata materiil dan spirituil berdasarkan Pancasila di dalam wadah Negara Kesatuan Republik Indonesia yang merdeka, berdaulat, bersatu dan berkedaulatan rakyat dalam suasana aman, tertib dan dinamis serta dalam lingkungan pergaulan dunia yang merdeka, bersahabat, tertib dan damai. Dalam rangka pencapaian tujuan tersebut maka pemerintah harus dapat memanfaatkan secara maksimal sumber daya yang ada serta seluruh potensi yang ada secara maksimal dan jujur.

Pembangunan Nasional yang selama ini dilaksanakan oleh pemerintah cenderung sentralistik dan terpusat, hal tersebut tercermin dengan berperannya kota-kota besar seperti Jakarta sebagai kota yang mempunyai multi fungsi. Dalam hal ini adalah sebagai pusat pemerintahan, pusat bisnis, pusat industri dan lain sebagainya. Terpusatnya perekonomian di Indonesia dipicu dengan tersedianya faktor-faktor produksi dan potensi pasar, tetapi juga disebabkan dengan adanya pusat birokrasi yang terjadi. Dengan adanya fenomena di atas, menunjukkan bahwa adanya hubungan yang signifikan kegiatan birokrasi dengan kegiatan usaha ekonomi di Indonesia yang cenderung sentralistik. Keadaan tersebut secara tidak langsung akan menghambat perkembangan daerah dan menyebabkan adanya kesenjangan ekonomi antara pusat dan daerah semakin tajam.

Salah satu upaya untuk mengatasi permasalahan tersebut maka pemerintah daerah berusaha untuk memperdayakan tingkat kemampuan ekonomi masing-masing sektor. Hal tersebut mengingat kemampuan masing-masing daerah untuk menciptakan pendapatan asli daerah mempunyai korelasi yang positif terhadap eksis dan tidaknya kemampuan yang telah dimiliki. 
Tolok ukur ini menjadi sangat penting dan menjadi pilihan fundamental untuk digunakan dalam rangka untuk menyikapi perubahan yang begitu cepat itu betul-betul terjadi. Seiring dengan prinsip demokrasi, iklim perubahan akan memberikan kontribusi dalam memberikan ruang dan peran serta masyarakat secara terbuka.

Terkait dengan fenomena tersebut maka tingkat kemampuan daerah dengan pemanfaatan sumber daya yang dimiliki merupakan syarat wajib yang harus digali dan dimanfaatkan secara maksimal. Kenyataan tersebut akibat adanya pandangan secara umum yang lebih disandarkan pada asumsi dengan besarnya pendapatan asli daerah yang telah dimiliki suatu daerah. Kenyataan menunjukkan bahwa di Indonesia saat ini banyak terdapat kesenjangan atau ketimpangan pembangunan antar suatu daerah, hal tersebut dapat diketahui pada tingkat pembangunan antara kawasan barat Indonesia dan kawasan timur Indonesia. Kenyataan tersebut menunjukkan bahwa pembangunan kawasan barat Indonesia menjadi pusat-pusat pertumbuhan atau pengembangan pembangunan, sehingga yang terjadi yaitu adanya perbedaan yang sangat mencolok dari kedua wilayah tersebut.

Pulau Madura merupakan salah satu kepulauan di propinsi Jawa Timur yang memiliki potensi yang besar pada bidang pertanian, potensi laut dan potensi sumber daya pertambangan serta energi yang cukup menjanjikan. Namun demikian pengolahan serta pemanfaatan potensi-potensi yang ada ini belum dilakukan secara optimal sehingga tingkat pembangunan yang ada di Pulau Madura belum maksimal. Dampak yang terjadi dengan adanya kondisi tersebut yaitu kurangnya tingkat kesejahteraan dan adanya kesejangan pada wilayah kota atau Kabupaten yang terdapat di Pulau Madura.

Sedangkan potensi ekonomi yang dipunyai Madura meliputi tembakau, mente, kelapa, dan Kapuk randu. Madura juga telah menjadi penghasil dan pengekspor utama garam. Untuk potensi sosial budaya Madura mempunyai beberapa hal yang unik yaitu antara lain Karapan Sapi, Batik Madura, semangat kesetiakawanan yang tinggi, terbuka 
dan ulet. Pulau Madura terdiri dari empat kabupaten mulai dari Bangkalan, Sampang, Pamekasan dan Sumenep dengan jumlah pulau-pulau kecil yang mencapai 127 pulau.

Segala upaya oleh pemerintah daerah Propinsi Jawa Timur untuk memaksimalkan segala potensi yang dimiliki oleh Pulau Madura, dimana salah satunya yaitu dengan dibangunnya Jembatan Suramadu yang merupakan akses yang paling cepat untuk menghubungkan kota di Jawa Timur ke Pulau Madura. Dengan dibangunnnya jembatan Suramadu secara langsung dapat memberikan dukungan atau dampak positif untuk mengembangkan potensi yang dimiliki Pulau Madura dan tidak lagi terpusat di wilayah Surabaya dan sekitarnya. Bertitik tolak dari latar belakang di atas, maka secara khusus akan dibahas mengenai kondisi tersebut melalui penelitian dengan judul "Analisis Pertumbuhan Ekonomi, Sektor Unggulan Dan Kesenjangan Pada Empat Kabupaten Di Pulau Madura”

\section{METODE PENELITIAN}

Penelitian ini memiliki tujuan utama untuk mengetahui atau menganalisa tingkat pertumbuhan ekonomi, sektor unggulan dan kesenjangan pada empat kabupaten di Pulau Madura selama kurun waktu 2005-2009, dari tujuan diatas maka peneliti melakukan penelitian dengan mengambil data-data sekunder yang dipublikasikan oleh kantor statistik pada empat kabupaten yang ada di Pulau Madura (Bangkalan, Sampang, Pamekasan dan Sumenep) dan instansi terkait.. Adapun alat-alat analisis yang digunakan untuk menganalisis data adalah Analisis Location Quotient (LQ), Analisis Tipologi Klassen, dan Analisis Analisis Indeks Williamson.

\section{PEMBAHASAN}

Hasil analisis pertumbuhan PDRB dan perkembangan PDRB per kapita untuk tiap kabupaten di pulau Madura selama kurun waktu tahun 2005-2009, beserta rata-ratanya untuk seluruh kabupaten di pulau Madura (Bangkalan, Sampang, Pamekasan dan Sumenep) (dapat dilihat pada tabel 1). 
Tabel 1. Pertumbuhan PDRB Kabupaten Bangkalan Atas Dasar Harga Konstan Tahun 2000 (\%)

\begin{tabular}{|c|c|c|c|c|}
\hline Sektor & 2006 & 2007 & 2008 & 2009 \\
\hline Pertanian & 1,91 & 0,78 & 6,94 & 4,45 \\
\hline Pertambangan & 13,48 & 3,77 & $(6,57)$ & $(2,96)$ \\
\hline Industri & 0,48 & 3,92 & 2,52 & 2,92 \\
\hline Listrik, gas \&Air & 3,34 & 1,70 & $(4,44)$ & $(2,34)$ \\
\hline Bangunan & 14,53 & 14,50 & 2,02 & 5,21 \\
\hline Perdagangan & 3,92 & 8,14 & 4,05 & 6,59 \\
\hline Pengangkutan & 6,14 & 3,82 & 4,24 & $(1,52)$ \\
\hline Keuangan & 9,13 & 7,78 & 5,14 & 1,42 \\
\hline Jasa-jasa & 7,20 & 6,35 & 3,93 & 5,45 \\
\hline PDRB & 4,57 & 5,06 & 4,58 & 4,43 \\
\hline
\end{tabular}

Sumber : BPS Kabupaten Bangkalan 2011.

Suatu perekonomian dikatakan mengalami pertumbuhan apabila tingkat kegiatan ekonomi lebih tinggi dari apa yang telah dicapai pada masa sebelumnya. Artinya, pertumbuhan baru tercipta apa bila jumlah barang dan jasa yang dihasilkan dalam perekonomian tersebut menjadi bertambah besar pada tahun-tahun berikutnya.

Pada tabel 1 dapat dilihat pertumbuhan Produk Domestik Regional Bruto (PDRB) Kabupaten Bangkalan selama kurun waktu 20062009 menurut harga konstan. PDRB mengalami penurunan pada tahun 2008 dan menurun lagi pada tahun 2009. Untuk tahun 2006 pertumbuhan ekonomi pada sektor Bangunan mencapai nilai tertinggi yaitu sebesar $14,53 \%$ dan terendah pada sektor Industri sebesar 0,48\%. Sedangkan untuk tahun 2007 nilai produksi pada sektor Bangunan mencapai pertumbuhan yang masih seimbang dengan tahun 2006 yaitu sebesar 14,50\%. Sedangkan pada tahun 2008 semua sektor mengalami penurunan hampir semua sektor akan tetapi hanya di bidang Pertanian mengalami peningkatan yaitu sebesar 6,94\%, sedangkan pada bidang Pertambangan dan Listrik, Gas \& Air, mengalami penurunan yang sangat signifikan yaitu sebesar $-6,57 \%$ dan $-4,44 \%$. Pada tahun 2009 pertumbuhan tertinggi pada sektor perdagangan sebesar 6,59\%. Angka terendah pada sektor Pertambangan yaitu $-2,96 \%$.

Dalam tabel 2 dapat dilihat pertumbuhan Produk Domestik Regional Bruto (PDRB) Kabupaten Sampang selama kurun waktu 20062009 menurut harga konstan 
mengalami fluktuasi. Dimana yaitu $-2,61 \%$. Sedangkan untuk tahun angkanya menurun pada tahun 2007 , 2007 nilai tertinggi pada sektor yaitu dari 4,41\% pada 2006 menjadi Keuangan yaitu mencapai $10,87 \%$, $4,33 \%$. Angka tersebut mengalami kenaikan pada tahun 2008 sebesar $4,67 \%$ dan mengalami penurunan kembali pada tahun 2009, yaitu sebesar 4,22 \%. Untuk tahun 2006 pertumbuhan ekonomi pada sektor Pengangkutan mencapai nilai tertinggi yaitu sebesar $7,32 \%$ dan yang terendah pada sektor bangunan dan yang terendah $0,73 \%$. Sedangkan tahun 2008 tertinggi pada sektor Pengangkutan $9,52 \%$ dan terendah pada sektor Listrik, Gas \& Air sebesar $-1,97 \%$, pada tahun 2009 pertumbuhan ekonomi tertinggi pada sektor Pengangkutan sebesar 9,87\% sedangkan terendah pada sektor Listrik, Gas \& Air sebesar 0,85\%.

\section{Tabel 2. Pertumbuhan PDRB Kabupaten Sampang Atas Dasar Harga} Konstan Tahun $2000(\%)$

\begin{tabular}{lcccc}
\hline \multicolumn{1}{c}{ Sektor } & 2006 & 2007 & 2008 & 2009 \\
\hline Pertanian & 4,2 & 0,73 & 2,08 & 1,91 \\
Pertambangan & 4,94 & 6,58 & 7,23 & 2,22 \\
Industri & 3,16 & 3,46 & 6,34 & 1,11 \\
Listrik, gas\&Air & 1,11 & 4,16 & $(1,97)$ & 0,85 \\
Bangunan & $(2,61)$ & 2,11 & 3,01 & 7,05 \\
Perdagangan & 6,33 & 10,64 & 7,55 & 7,54 \\
Pengangkutan & 7,32 & 7,28 & 9,52 & 9,87 \\
Keuangan & 5,71 & 10,87 & 7,9 & 5,54 \\
Jasa-jasa & 3,09 & 4,97 & 6,77 & 7,4 \\
PDRB & 4,41 & 4,33 & 4,67 & 4,22 \\
\hline
\end{tabular}

Sumber : BPS Kabupaten Sampang 2011.

Tabel 3. Pertumbuhan PDRB Kabupaten Pamekasan Atas Dasar Harga Konstan Tahun 2000 (\%)

\begin{tabular}{lcccc}
\hline \multicolumn{1}{c}{ Sektor } & 2006 & 2007 & 2008 & 2009 \\
\hline Pertanian & 4,66 & 2,65 & 3,14 & 3,86 \\
Pertambangan & 5,13 & 4,02 & 3,16 & 0,1 \\
Industri & $(2,23)$ & 2,24 & 4,06 & $(0,19)$ \\
Listrik, gas\&Air & $(0,31)$ & 3,8 & 0,62 & $(0,25)$ \\
Bangunan & 4,11 & 4,71 & 7,2 & 5 \\
Perdagangan & 7,00 & 7,77 & 8,22 & 6,49 \\
Pengangkutan & 2,88 & 6,93 & 11,88 & 12,16 \\
Keuangan & 5,39 & 7,86 & 8,51 & 4,78 \\
Jasa-jasa & 3,91 & 5,8 & 6,65 & 7 \\
PDRB & 4,65 & 4,35 & 5,14 & 5,01 \\
\hline
\end{tabular}

Sumber : BPS Kabupaten Pamekasan 2011. 
Tabel 4. Pertumbuhan PDRB Kabupaten Sumenep Atas Dasar Harga

Konstan Tahun 2000 (\%)

\begin{tabular}{lcccc}
\hline \multicolumn{1}{c}{ Sektor } & 2006 & 2007 & 2008 & 2009 \\
\hline Pertanian & 4,59 & 2,93 & 2,01 & 2,54 \\
Pertambangan & $(1,62)$ & 3,66 & $(0,98)$ & 9,86 \\
Industri & $(5,92)$ & 2,09 & 5,06 & 2,55 \\
Listrik, gas\&Air & $(1,18)$ & 5,05 & 6,03 & 1,38 \\
Bangunan & 1,96 & 2,00 & 5,24 & 5,69 \\
Perdagangan & 4,67 & 8,51 & 7,39 & 5,23 \\
Pengangkutan & 3,99 & 6,70 & 8,72 & 8,16 \\
Keuangan & 8,89 & 10,35 & 10,94 & 6,34 \\
Jasa-jasa & 4,23 & 5,77 & 7,13 & 6,21 \\
PDRB & 4,08 & 4,60 & 4,10 & 4,15 \\
\hline
\end{tabular}

Sumber : BPS Kabupaten sumenep 2011.

Pada tabel 3 dapat dilihat pertumbuhan Produk Domestik Regional Bruto (PDRB) kabupaten Pamekasan selama kurun waktu 20062009 menurut harga konstan mengalami fluktuasi. Dimana angkanya menurun pada tahun 2007 , yaitu dari 4,35\% pada 2006 menjadi 4,65 \%. Angka tersebut mengalami kenaikan pada tahun 2008 sebesar 5,14 $\%$ dan mengalami penurunan kembali pada tahun 2009, yaitu sebesar 5,01\% Untuk tahun 2006 pertumbuhan ekonomi pada sektor Keuangan mencapai nilai tertinggi yaitu sebesar $7,00 \%$ dan yang terendah pada sektor industri yaitu $-2,23 \%$. Sedangkan untuk tahun 2007 nilai tertinggi tetap pada sektor Keuangan yaitu mencapai $7,86 \%$, dan yang terendah pada sektor $2,24 \%$. Sedangkan tahun 2008 tertinggi pada sektor Pengangkutan sebesar 11,88 \% dan terendah pada sektor Listrik, Gas \& Air sebesar 0,62 $\%$, sedangkan pada tahun 2009 Pertumbuhan ekonomi tertinggi pada sektor Pengangkutan sebesar 12,16\% sedangkan terendah pada sektor Listrik, Gas \& Air yaitu sebesar $-0,25 \%$.

Dalam tabel 4 dapat dilihat pertumbuhan Produk Domestik Regional Bruto (PDRB) kabupaten Samenep selama kurun waktu 20062009 menurut harga konstan mengalami fluktuasi. Dimana angkanya meningkat pada tahun 2007, dari 4,08\% pada 2006 menjadi $4,60 \%$. Angka tersebut mengalami penurunan pada tahun 2008 sebesar $4,10 \%$ dan mengalami peningkatan kembali pada tahun 2009, yaitu sebesar 4,15\%. Untuk tahun 2006 pertumbuhan ekonomi pada sektor keuangan mencapai nilai tertinggi 
yaitu sebesar 8,89 \% dan yang terendah pada sektor industri yaitu $5,92 \%$. Sedangkan untuk tahun 2007 nilai tertinggi tetap pada sektor Keuangan yaitu mencapai 10,35\%. Dan yang terendah pada sektor Bangunan yaitu sebesar 2,00 \%. Sedangkan tahun 2008 tertinggi pada sektor Pengangkutan sebesar 10,94\% dan terendah pada sektor pertambangan sebesar yaitu $-0,98 \%$, pada tahun 2009 pertumbuhan ekonomi tertinggi pada sektor Pertambangan sebesar $9,86 \%$ sedangkan terendah pada sektor Listrik, Gas dan Air yaitu 1,38\%.

Bila diamati dari pertumbuhan ekonomi yang terjadi, maka dapat diketahui pola pertumbuhan ekonomi pada empat kabupaten di Pulau Madura. Analisis Tipologi Klassen di gunakan untuk mengetahui gambaran tentang pola pertumbuhan ekonomi pada daerah atau kabupaten. Tipologi klassen pada dasarnya membagi daerah berdasarkan dua indikator utama, yaitu pertumbuhan ekonomi daerah dan pendapatan perkapita daerah. Kreteria yang di gunakan untuk membagi daerah kabupaten / kota dalam penelitian ini sebagai berikut : (1). Daerah cepat maju dan cepat tumbuh yaitu, daerah yang memiliki tingkat pertumbuhan ekonomi dan pendapatan per kapita yang lebih tinggi dibandingkan ratarata kabupaten di Madura; (2).Daerah maju tapi tertekan yaitu, daerah yang memiliki perdapatan perkapita lebih ntinggi, tetapi tingkat pertumbuhan ekonomi nya lebih rendah di bandingkan rata-rata pulau Madura; (3).Daerah berkembang cepat adalah daerah yang memiliki tingkat pertumbuhan ekonomi tinggi, tetapi tingkat pendapatan perkapita lebih rendah dibanding rata-rata pulau Madura; (4).Daerah relatif tertinggal adalah daerah yang memiliki tingkat pertumbuhan ekonomi dan pendapatan perkapita yang lebih rendah di bandingkan rata-rata pulau Madura.

Hasil analisis PDRB per kapita dan pertumbuhan PDRB pada masing-masing kabupaten di pulau Madura selama kurun waktu tahun 2005-2009, beserta rata-ratanya untuk seluruh kabupaten di pulau Madura (dapat dilihat pada tabel 5). 
Tabel 5. PDRB Per Kapita \& Pertumbuhan PDRB Di Pulau Madura Atas Dasar Harga Konstan Tahun 2005-2009 (\%)

\begin{tabular}{lccc}
\hline & Kabupaten & PDRB Per Kapita & Pertumbuhan PDRB \\
\hline Bangkalan & $3.222 .146,78$ & 4,66 \\
Sampang & $2.696 .863,19$ & 4,46 \\
Pamekasan & $2.228 .700,15$ & 4,79 \\
Sumenep & & $4.588 .718,04$ & 4,24 \\
& Rata-rata & $3.184 .107,04$ & 4,54 \\
\hline
\end{tabular}

Sumber : BPS 4 Kabupaten di pulau Madura 2011.

Tabel 6. Pola Pertumbuhan Ekonomian Masing-Masing Daerah Di Pada Empat Kabupaten di Pulau Madura

\begin{tabular}{lccl}
\hline \multicolumn{1}{c}{ Kabupaten } & $\begin{array}{c}\text { Pertumbuhan } \\
\text { PDRB }\end{array}$ & $\begin{array}{c}\text { PDRB Per } \\
\text { Kapita }\end{array}$ & \multirow{2}{*}{ Kriteria } \\
\hline Bangkalan & TINGGI & TINGGI & CEPAT MAJU DAN TUMBUH \\
Sampang & RENDAH & RENDAH & RELATIF TERTINGGAL \\
Pamekasan & TINGGI & RENDAH & BERKEMBANG CEPAT \\
Sumenep & RENDAH & TINGGI & MAJU TAPI TERTEKAN \\
\hline
\end{tabular}

Sumber : BPS 4 Kabupaten di pulau Madura 2011.

Tabel 7. Identifikasi sektor unggulan pada kabupaten Bangkalan Tahun 2005-2009

\begin{tabular}{lcccccc}
\hline \multicolumn{1}{c}{ Sektor } & 2005 & 2006 & 2007 & 2008 & 2009 & Average \\
\hline Pertanian & 0,7 & 0,69 & 0,68 & 0,7 & 0,71 & 0,70 \\
Pertambangan & 0,4 & 0,44 & 0,43 & 0,4 & 0,37 & 0,34 \\
Industri & 1,74 & 1,78 & 1,79 & 1,76 & 1,77 & 1,77 \\
Listrik, Gas \& Air & 1,35 & 1,38 & 1,35 & 1,31 & 1,29 & 1,34 \\
Bangunan & 1,52 & 1,63 & 1,73 & 1,7 & 1,69 & 1,65 \\
Perdagangan & 1,43 & 1,41 & 1,4 & 1,36 & 1,37 & 1,39 \\
Pengangkutan & 1,69 & 1,7 & 1,67 & 1,62 & 1,52 & 1,64 \\
Keuangan & 1,1 & 1,11 & 1,09 & 1,06 & 1,02 & 1,08 \\
Jasa-jasa & 1,17 & 1,2 & 1,2 & 1,17 & 1,77 & 1,30 \\
\hline
\end{tabular}

Sumber : BPS Kabupaten Bangkalan 20011

Berdasarkan analisa Tipologi pertama adalah "Daerah cepat maju Klassen pada tabel 6 dapat dilihat dan cepat tumbuh" yang termasuk pola pertumbuhan ekonomi pada dalam klasifikasi ini yaitu kabupaten empat kabupaten di pulau Madura. Bangkalan. Yang kedua adalah Dengan analisis tipologi Klassen pada "Daerah тији tapi tertekan" yaitu empat kabupaten di pulau Madura dapat di klasifikasikan menjadi empat pola pertumbuhan ekonomi, yang kabupaten Sumenep. Yang ketiga adalah "Daerah berkembang cepat" yaitu kabupaten Pamekasan. Dan 
untuk yang keempat atau yang terahir

"Daerah relatif tertinggal" yang termasuk dalam klasifikasi ini yaitu kabupaten Sampang.

Pembahasan berikutnya menggunakan Analisis Location Quentiens (LQ) yang dapat menunjukkan bahwa suatu kabupaten baik yang memilik sektor ungglan atau tidak, memiliki nilai LQ yang lebih besar dari 1(satu) pada beberapa sektor lapangan usaha. Hal tersebut menunjukkan bahwa pada masing- masing kabupaten yang ada di pulau Madura memiliki sektor unggulan. Hasil perhitungan analisis Location Quentiens (LQ) untuk mengetahui sektor-sektor unggulan di empat kabupaten di pulau Madura yang nantinya merupakan potensi daerah. Sektor unggulan terhadap Produk Domestik Regional Bruto (PDRB) untuk tahun 2005 hingga tahun 2009 kabupaten Bangkalan terlihat pada tabel 7 .

Tabel 8. Kode nilai LQ kabupaten Bangkalan tahun 2005-2009

\begin{tabular}{lcccccc}
\hline \multicolumn{1}{c}{ Sektor } & 2005 & 2006 & 2007 & 2008 & 2009 & Average \\
\hline Pertanian & $\mathrm{NU}$ & $\mathrm{NU}$ & $\mathrm{NU}$ & $\mathrm{NU}$ & $\mathrm{NU}$ & $\mathrm{NU}$ \\
Pertambangan & $\mathrm{NU}$ & $\mathrm{NU}$ & $\mathrm{NU}$ & $\mathrm{NU}$ & $\mathrm{NU}$ & $\mathrm{NU}$ \\
Industri & $\mathrm{U}$ & $\mathrm{U}$ & $\mathrm{U}$ & $\mathrm{U}$ & $\mathrm{U}$ & $\mathrm{U}$ \\
Listrik, Gas \& Air & $\mathrm{U}$ & $\mathrm{U}$ & $\mathrm{U}$ & $\mathrm{U}$ & $\mathrm{U}$ & $\mathrm{U}$ \\
Bangunan & $\mathrm{U}$ & $\mathrm{U}$ & $\mathrm{U}$ & $\mathrm{U}$ & $\mathrm{U}$ & $\mathrm{U}$ \\
Perdagangan & $\mathrm{U}$ & $\mathrm{U}$ & $\mathrm{U}$ & $\mathrm{U}$ & $\mathrm{U}$ & $\mathrm{U}$ \\
Pengangkutan & $\mathrm{U}$ & $\mathrm{U}$ & $\mathrm{U}$ & $\mathrm{U}$ & $\mathrm{U}$ & $\mathrm{U}$ \\
Keuangan & $\mathrm{U}$ & $\mathrm{U}$ & $\mathrm{U}$ & $\mathrm{U}$ & $\mathrm{U}$ & $\mathrm{U}$ \\
Jasa-jasa & $\mathrm{U}$ & $\mathrm{U}$ & $\mathrm{U}$ & $\mathrm{U}$ & $\mathrm{U}$ & $\mathrm{U}$ \\
\hline
\end{tabular}

Keterangan: NU = Non Unggulan; $\mathrm{U}=$ Unggulan

Sumber : BPS Kabupaten Bangkalan 2011

Tabel 9. Identifikasi sektor unggulan pada kabupaten Sampang Tahun 20052009

\begin{tabular}{lcccccc}
\hline \multicolumn{1}{c}{ Sektor } & 2005 & 2006 & 2007 & 2008 & 2009 & Average \\
\hline Pertanian & 1,01 & 1 & 1 & 1 & 1,03 & 1,01 \\
Pertambangan & 2,16 & 2,20 & 2,24 & 2,34 & 2,29 & 2,69 \\
Industri & 0,36 & 0,38 & 0,38 & 0,39 & 0,39 & 0,38 \\
Listrik, Gas \& Air & 1,45 & 1,44 & 1,46 & 1,45 & 1,47 & 1,45 \\
Bangunan & 0,93 & 0,85 & 0,81 & 0,8 & 0,81 & 0,84 \\
Perdagangan & 1 & 1,01 & 1,03 & 1,04 & 1,05 & 1,02 \\
Pengangkutan & 0,57 & 0,58 & 0,59 & 0,6 & 0,63 & 0,59 \\
Keuangan & 0,8 & 0,79 & 0,8 & 0,8 & 0,81 & 0,80 \\
\hline
\end{tabular}




\begin{tabular}{lllllll}
\hline Jasa-jasa & 0,9 & 0,89 & 0,88 & 0,89 & 0,9 & 0,89 \\
\hline
\end{tabular}

Sumber: BPS Kabupaten Samapang 2011.

Pada tabel 8 menunjukkan bahwa dengan analisis LQ kabupaten Bangkalan dapat dijelaskan bahwa sektor yang merupakan sektor unggulan di kabupaten Bangkalan adalah Industri, Listrik, Gas \& air, Bangunanan, Perdagangan, Pengangkutan, keuanganan dan Jasajasa. Sektor tersebut dapat dinyatakan sebagai sektor unggulan karena sektor-sektor tersebut mempunyai nilai LQ lebih besar dari 1 (satu). Hal ini berarti pula bahwa sektor tersebut merupakan suatu potensi kabupaten yang dapat terus dikembangkan untuk mendukung pertumbuhan ekonomi kabupaten bangkalan. Sedangkan untuk sektor pertanian dan pertambangan bukan merupakan sektor unggulan dimana nilai LQ nya lebih kecil dari satu, hal ini dapat diperhatikan supaya dua sektor yang belum termasuk sektor unggulan dapat dikembangkan kembali agar dapat menjadi sektor unggulan dan dapat membantu pertumbuhan PDRB di kabupaten setempat.

Kontribusi sektor-sektor unggulan di kabupaten Bangkalan mengalami fluktuasi dari tahun 2005 sampai dengan tahun 2009. Rata-rata pertumbuhan nilai LQ nya untuk masing-masing sektor unggulan adalah Industri sebesar 1,77, Listrik, Gas \& Air sebesar 1,34, bangunanan sebesar 1,65, Perdagangan sebesar 1,39, Pengangkutan sebesar 1,64, Keuanganan sebesar 1,08 dan Jasajasa sebesar 1,30.

Jadi sektor yang merupakan sektor unggulan di kabupaten Bangkalan adalah Industri, Listrik, Gas \& Air, Bangunanan, Perdagangan, Pengangkutan, Keuanganan dan Jasa-jasa, dan yang bukan merupakan sektor unggulan adalah Pertanian dan pertambangan. Sektor unggulan terhadap Produk Domestik Regional Bruto (PDRB) untuk tahun 2005 hingga tahun 2009 kabupaten Sampang terlihat pada tabel 9 .

Tabel 10 menunjukkan bahwa dengan analisis LQ kabupaten sampang dapat dijelaskan bahwa sektor yang merupakan sektor unggulan di kabupaten Sampang adalah Pertanian, Pertambangan, Listrik, Gas \&Air, dan Perdagangan. Sektor tersebut dapat dinyatakan 
sebagai sektor unggulan karena sektor-sektor tersebut mempunyai nilai LQ lebih besar dari 1 (satu). Hal ini berarti pula bahwa sektor tersebut merupakan suatu potensi kabupaten yang dapat terus dikembangkan untuk mendukung pertumbuhan ekonomi kabupaten Sampang. Sedangkan untuk sektor Industri, Bangunanan, pengangkutan, Keuanganan dan Jasajasa bukan merupakan sektor unggulan dimana nilai LQ nya lebih kecil dari satu dan pertanian yang juga merupakan sektor unggulan dapat dikembangkan kembali agar dapat menjadi sektor ungglan, hal ini dapat diperhatikan supaya sektor tersebut, yang belum termasuk sektor unggulan dapat dikembangkan kembali agar dapat menjadi sektor unggulan dan dapat membantu pertumbuhan PDRB di kabupaten setempat.

\section{Kontribusi}

sektor-sektor unggulan di kabupaten Sampang mengalami fluktuasi dari tahun 2005 sampai dengan tahun 2009. Rata-rata pertumbuhan nilai LQ nya untuk masing-masing sektor unggulan adalah Pertanian sebesar 1,01, Pertambangan sebesar 2,69, Listrik, Gas \& Air sebesar 1,45 dan Perdagangan sebesar 1,02. Jadi sektor yang merupakan sektor unggulan di kabupaten Sampang, adalah Pertambangan, Listrik, Gas \& Air dan Perdagangan. Dan yang bukan merupakan sektor unggulan adalah Pertanian dan Pertambangan, Industri, Bangunanan, Pengangkutan, Keuanganan dan Jasa-jasa. Sektor unggulan terhadap Produk Domestik Regional Bruto (PDRB) untuk tahun 2005 hingga 2009 kabupaten Pamekasan terlihat pada tabel 11.

Tabel 10. Kode nilai LQ kabupaten Sampang tahun 2005-2009

\begin{tabular}{lcccccc}
\hline \multicolumn{1}{c}{ Sektor } & 2005 & 2006 & 2007 & 2008 & 2009 & Average \\
\hline Pertanian & $\mathrm{U}$ & $\mathrm{U}$ & $\mathrm{U}$ & $\mathrm{U}$ & $\mathrm{U}$ & $\mathrm{U}$ \\
Pertambangan & $\mathrm{U}$ & $\mathrm{U}$ & $\mathrm{U}$ & $\mathrm{U}$ & $\mathrm{U}$ & $\mathrm{U}$ \\
Industri & $\mathrm{NU}$ & $\mathrm{NU}$ & $\mathrm{NU}$ & $\mathrm{NU}$ & $\mathrm{NU}$ & $\mathrm{NU}$ \\
Listrik, Gas \& Air & $\mathrm{U}$ & $\mathrm{U}$ & $\mathrm{U}$ & $\mathrm{U}$ & $\mathrm{U}$ & $\mathrm{U}$ \\
Bangunan & $\mathrm{NU}$ & $\mathrm{NU}$ & $\mathrm{NU}$ & $\mathrm{NU}$ & $\mathrm{NU}$ & $\mathrm{NU}$ \\
Perdagangan & $\mathrm{U}$ & $\mathrm{U}$ & $\mathrm{U}$ & $\mathrm{U}$ & $\mathrm{U}$ & $\mathrm{U}$ \\
Pengangkutan & $\mathrm{NU}$ & $\mathrm{NU}$ & $\mathrm{NU}$ & $\mathrm{NU}$ & $\mathrm{NU}$ & $\mathrm{NU}$ \\
Keuangan & $\mathrm{NU}$ & $\mathrm{NU}$ & $\mathrm{NU}$ & $\mathrm{NU}$ & $\mathrm{NU}$ & $\mathrm{NU}$ \\
\hline
\end{tabular}




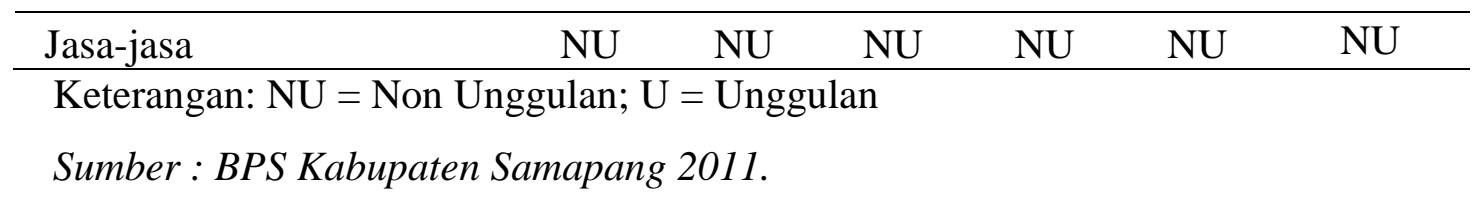

Tabel 11. Identifikasi sektor unggulan pada kabupaten Pamekasan Tahun 2005-2009

\begin{tabular}{lcccccc}
\hline \multicolumn{1}{c}{ Sektor } & 2005 & 2006 & 2007 & 2008 & 2009 & Average \\
\hline Pertanian & 1,11 & 1,12 & 1,13 & 1,12 & 1,12 & 1,12 \\
Pertambangan & 0,33 & 0,33 & 0,33 & 0,33 & 0,31 & 0,27 \\
Industri & 0,43 & 0,43 & 0,42 & 0,42 & 0,41 & 0,42 \\
Listrik, Gas \& Air & 1,99 & 1,96 & 1,97 & 2 & 2 & 1,98 \\
Bangunan & 1,3 & 1,27 & 1,24 & 1,27 & 1,26 & 1,27 \\
Perdagangan & 0,63 & 0,64 & 0,64 & 0,64 & 0,64 & 0,64 \\
Pengangkutan & 0,95 & 0,93 & 0,94 & 0,98 & 1,04 & 0,97 \\
Keuangan & 1,34 & 1,3 & 1,29 & 1,28 & 1,28 & 1,30 \\
Jasa-jasa & 1,28 & 1,26 & 1,27 & 1,27 & 1,27 & 1,27 \\
\hline
\end{tabular}

Sumber: BPS Kabupaten Pamekasan 2011.

Tabel 12. Kode nilai LQ kabupaten Sampang tahun 2005-2009

\begin{tabular}{lcccccc}
\hline \multicolumn{1}{c}{ Sektor } & 2005 & 2006 & 2007 & 2008 & 2009 & Average \\
\hline Pertanian & $\mathrm{U}$ & $\mathrm{U}$ & $\mathrm{U}$ & $\mathrm{U}$ & $\mathrm{U}$ & $\mathrm{U}$ \\
Pertambangan & $\mathrm{NU}$ & $\mathrm{NU}$ & $\mathrm{NU}$ & $\mathrm{NU}$ & $\mathrm{NU}$ & $\mathrm{NU}$ \\
Industri & $\mathrm{NU}$ & $\mathrm{NU}$ & $\mathrm{NU}$ & $\mathrm{NU}$ & $\mathrm{NU}$ & $\mathrm{NU}$ \\
Listrik, Gas \& Air & $\mathrm{U}$ & $\mathrm{U}$ & $\mathrm{U}$ & $\mathrm{U}$ & $\mathrm{U}$ & $\mathrm{U}$ \\
Bangunan & $\mathrm{U}$ & $\mathrm{U}$ & $\mathrm{U}$ & $\mathrm{U}$ & $\mathrm{U}$ & $\mathrm{U}$ \\
Perdagangan & $\mathrm{NU}$ & $\mathrm{NU}$ & $\mathrm{NU}$ & $\mathrm{NU}$ & $\mathrm{NU}$ & $\mathrm{NU}$ \\
Pengangkutan & $\mathrm{NU}$ & $\mathrm{NU}$ & $\mathrm{NU}$ & $\mathrm{NU}$ & $\mathrm{U}$ & $\mathrm{NU}$ \\
Keuangan & $\mathrm{U}$ & $\mathrm{U}$ & $\mathrm{U}$ & $\mathrm{U}$ & $\mathrm{U}$ & $\mathrm{U}$ \\
Jasa-jasa & $\mathrm{U}$ & $\mathrm{U}$ & $\mathrm{U}$ & $\mathrm{U}$ & $\mathrm{U}$ & $\mathrm{U}$ \\
\hline
\end{tabular}

Keterangan: NU = Non Unggulan; $\mathrm{U}=$ Unggulan

Sumber : BPS Kabupaten Pamekasan 2011.

Tabel 11 menunjukkan bahwa dengan analisis LQ kabupaten Pamekasan dapat dijelaskan bahwa sektor yang merupaka sektor unggulan di kabupaten Pamekasan adalah Pertanian, Listrik, Gas \& Air, Bangunanan, Keuanganan dan Jasajasa. Sektor tersebut dapat dinyatakan sebagai sektor unggulan karena sektor-sektor tersebut mempunyai nilai LQ lebih besar dari 1 (satu). Hal ini berarti pula bahwa sektor tersebut merupakan suatu potensi kabupaten yang dapat terus dikembangkan untuk mendukung pertumbuhan ekonomi kabupaten Bangkalan. Sedangkan 
untuk sektor Petambangan, Industri, Perdagangan dan Pengangkutan bukan merupakan sektor unggulan dimana nilai LQ nya lebih kecil dari satu, hal ini dapat diperhatikan supaya sektor-sektor yang belum termasuk sektor unggulan dapat dikembangkan kembali agar dapat menjadi sektor unggulan dan dapat membantu pertumbuhan PDRB di kabupaten setempat.

Kontribusi sektor-sektor unggulan di kabupaten Pamekasan mengalami fluktuasi dari tahun 2005 sampai dengan tahun 2009. Rata-rata pertumbuhan nilai LQ nya untuk masing-masing sektor unggulan adalah Pertanian sebesar 1,12, Listrik, Gas \& Air sebesar 1,98, Bangunanan sebesar 1,27, Keuanganan sebesar 1,30 dan Jasa-jasa sebesar 1,27. Jadi sektor yang merupakan sektor unggulan di kabupaten Pamekasan adalah Pertanian, Listrik, Gas \& air, Bangunanan, Keuanganan dan JasaJasa, dan yang bukan merupakan sektor unggulan adalah Petambangan, Industri, Perdagangan dan Pengangkutan. Sektor unggulan terhadap Produk Domestik Regional Bruto (PDRB) untuk tahun 2005 hingga tahun 2009 Kabupaten Sumenep terlihat pada tabel 13 .

Berdasarkan tabel 14 menunjukkan bahwa dengan analisis LQ kabupaten Sumenep dapat dijelaskan bahwa sektor yang merupakan sektor unggulan di kabupaten Sumenep adalah pertanian, pertambangan dan industri Sektor tersebut dapat dinyatakan sebagai sektor unggulan karena sektor-sektor tersebut mempunyai nilai LQ lebih besar dari 1 (satu). Hal ini berarti pula bahwa sektor tersebut merupakan suatu potensi kabupaten yang dapat terus dikembangkan untuk mendukung pertumbuhan ekonomi kabupaten Sumenep. Sedangkan untuk sektor Listrik, Gas dan Air, Bangunan, Perdagangan, Pengangkutan, Keuanganan dan Jasajasa. bukan merupakan sektor unggulan dimana nilai LQ nya lebih kecil dari satu, hal ini dapat diperhatikan supaya sektor-sektor yang belum termasuk sektor unggulan dapat dikembangkan kembali agar dapat menjadi sektor unggulan dan dapat membantu pertumbuhan PDRB di kabupaten setempat. 
Tabel 13. Identifikasi sektor unggulan pada kabupaten Sumenep Tahun 2005-2009

\begin{tabular}{lcccccc}
\hline \multicolumn{1}{c}{ Sektor } & 2005 & 2006 & 2007 & 2008 & 2009 & Average \\
\hline Pertanian & 1,14 & 1,15 & 1,16 & 1,16 & 1,15 & 1,15 \\
Pertambangan & 1,06 & 1,01 & 1 & 1 & 1,02 & 1,02 \\
Industri & 1,07 & 1,03 & 1,03 & 1,04 & 1,04 & 1,04 \\
Listrik, gas\&Air & 0,16 & 0,16 & 0,16 & 0,18 & 0,18 & 0,17 \\
Bangunan & 0,59 & 0,56 & 0,53 & 0,54 & 0,55 & 0,55 \\
Perdagangan & 0,87 & 0,87 & 0,87 & 0,88 & 0,88 & 0,87 \\
Pengangkutan & 0,8 & 0,79 & 0,8 & 0,81 & 0,84 & 0,81 \\
Keuangan & 0,91 & 0,92 & 0,93 & 0,96 & 0,97 & 0,94 \\
Jasa-jasa & 0,83 & 0,83 & 0,83 & 0,84 & 0,84 & 0,83 \\
\hline
\end{tabular}

Sumber : BPS Kabupaten Sumenep 2011.

Tabel 14. Kode nilai LQ kabupaten Sumenep tahun 2005-2009

\begin{tabular}{lcccccc}
\hline \multicolumn{1}{c}{ Sektor } & 2005 & 2006 & 2007 & 2008 & 2009 & Average \\
\hline Pertanian & $\mathrm{U}$ & $\mathrm{U}$ & $\mathrm{U}$ & $\mathrm{U}$ & $\mathrm{U}$ & $\mathrm{U}$ \\
Pertambangan & $\mathrm{U}$ & $\mathrm{U}$ & $\mathrm{U}$ & $\mathrm{U}$ & $\mathrm{U}$ & $\mathrm{U}$ \\
Industri & $\mathrm{U}$ & $\mathrm{U}$ & $\mathrm{U}$ & $\mathrm{U}$ & $\mathrm{U}$ & $\mathrm{U}$ \\
Listrik, Gas \& Air & $\mathrm{NU}$ & $\mathrm{NU}$ & $\mathrm{NU}$ & $\mathrm{NU}$ & $\mathrm{NU}$ & $\mathrm{NU}$ \\
Bangunan & $\mathrm{NU}$ & $\mathrm{NU}$ & $\mathrm{NU}$ & $\mathrm{NU}$ & $\mathrm{NU}$ & $\mathrm{NU}$ \\
Perdagangan & $\mathrm{NU}$ & $\mathrm{NU}$ & $\mathrm{NU}$ & $\mathrm{NU}$ & $\mathrm{NU}$ & $\mathrm{NU}$ \\
Pengangkutan & $\mathrm{NU}$ & $\mathrm{NU}$ & $\mathrm{NU}$ & $\mathrm{NU}$ & $\mathrm{NU}$ & $\mathrm{NU}$ \\
Keuangan & $\mathrm{NU}$ & $\mathrm{NU}$ & $\mathrm{NU}$ & $\mathrm{NU}$ & $\mathrm{NU}$ & $\mathrm{NU}$ \\
Jasa-jasa & $\mathrm{NU}$ & $\mathrm{NU}$ & $\mathrm{NU}$ & $\mathrm{NU}$ & $\mathrm{NU}$ & $\mathrm{NU}$ \\
\hline
\end{tabular}

Keterangan: $\mathrm{NU}=$ Non Unggulan; $\mathrm{U}=$ Unggulan

Sumber : BPS Kabupaten Sumenep 2011.

Tabel 15. Sektor Unggulan Pada Masing-Masing Kabupaten.

\begin{tabular}{|c|c|}
\hline KABUPATEN & SEKTOR UNGGULAN \\
\hline Bangkalan & $\begin{array}{l}\text { Indutri, Listrik, Gas \&Air, Bangunan, Perdagangan, } \\
\text { Pengangkutan, Keuanagan dan jasa-jasa. }\end{array}$ \\
\hline Sampang & Pertanian, Pertambangan dan Listrik, Gas \& Air. \\
\hline Pamekasan & Pertanian, listrik, Gas \& Air, Bangunan, Keuangan dan Jasa-jasa. \\
\hline Sumenep & Pertanian, pertambangan dan Industri. \\
\hline
\end{tabular}

Sumber : BPS 4 Kabupaten di pulau Madura 2011.

Kontribusi sektor-sektor masing-masing sektor unggulan

unggulan di kabupaten Sumenep adalah Pertanian sebesar 1,15, mengalami fluktuasi dari tahun 2005 Pertambangan sebesar 1,02, dan sampai dengan tahun 2009. Rata-rata Industri sebesar 1,04. Jadi sektor yang pertumbuhan nilai LQ nya untuk merupakan sektor unggulan di 
kabupaten Sumenep adalah Pertanian, Pertambangan, dan Industri. Dan yang bukan merupakan sektor unggulan adalah Listrik, Gas \& air, Bangunanan, Perdagangan, Pengangkutan, Keuangan dan Jasajasa.

Secara umum sektor Pertanian, Pertambangan, Indutri, Listrik, Gas \& Air, Bangunan, Perdagangan, Pengangkutan, Keuanagan dan Jasajasa. Merupakan sektor unggulan pada empat kabupaten di pulau Madura artinya sektor yang dikembangkan/diprioritaskan masih pada sektor Pertanian, Pertambangan, Indutri, Listrik, Gas \& Air, Bangunan, Perdagangan, Pengangkutan, Keuanagan dan jasajasa, namun yang dominan di pulau Madura ada dua sektor Pertanian dan Listrik, Gas \& Air.

Manfaat mengetahui sektor unggulan yaitu mampu memberikan indikasi bagi perekonomian nasional dan regional. Sektor unggulan dipastikan memiliki potensi lebih besar untuk tumbuh lebih cepat di bandingkan sektor lainnnya dalam suatu daerah terutama adanya faktor pendukung terhadap sektor unggulan tersebut yaitu akumulasi modal, pertumbuhan tenaga kerja yang terserap dan kemajuan teknologi (technological progress). Penciptaan peluang investasi juga dapat di lakukan dengan memberdayakan potensi sektor unggulan yang dimiliki oleh empat kabupaten yang ada di pulau Madura (Bangkalan, Sampang, Pamekasan dan Sumenep).

Agar mengetahui kesenjangan di Pulau Madura dapat digunakan analisis Indek Williamson. Indek Williamson meneliti hubungan antara kesenjangan regional dengan tingkat pembangunan ekonomi, ditemukan bahwa selama tahapan awal pembangunan, kesenjangan regional menjadi lebih besar dan pembangunan lebih konsentrasi di daerah-daerah tertentu. pada tahapan yang lebih matang dilihat dari pertumbuhan ekonomi, tanpa adanya keseimbangan antar daerah dan kesenjangan berkurang secara signifikan.

Proses akumulasi dan mobilisasi sumber-sumber, berupa akumulasi modal, keterampilan tenaga kerja, dan sumber daya alam yang di miliki oleh suatu daerah merupakan pemicu dalam laju pertumbuhan ekonomi wilayah yang 
bersangkutan. Adanya heterogenitas dan karakteristik wilayah menyebabkan terjadinya ketimpangan antar daerah dan antar sektor ekonomi daerah. kesenjangan antara daerah merupakan konsekuensi logis pembangunan merupakan suatu tahapan perubahan dalam pembangunan itu sendiri.

Indek Williamson adalah suatu cara untuk mengukur kesenjangan atau ketimpangan antar daerah atau kabupaten dari distribusi pendapatan. Jika nilai Indek Williamson mendekati nol (0), maka tingkat ketimpangan distribusi pendapatan semakin kecil (semakin merata). sebaliknya jika nilai Indek Williamson semakin jauh dari nol (0) maka ketimpangan atau kesenjangan semakin melebar.

Hasil analisis Indek Williamson pada masing-masing kabupaten di pulau Madura selama kurun waktu tahun 2005-2009, beserta rata-ratanya untuk seluruh kabupaten di pulau Madura, dapat dilihat pada tabel 16.

Tabel 16 menunjukkan angka indeks williamson PDRB per kapita antar kabupaten yang ada di pulau Madura (Bangkalan, Sampang, Pamekasan, dan Sumenep) selama kurun waktu dari tahun 2005 sampai dengan tahun 2009. Indek Williamson terendah di kabupaten Bangkalan yaitu tahun 2006, 2008 \& 2009 sebesar 0,01, dan yang terbesar di tahun 2007 sebesar 0,17, sehingga kesenjangan pembagunan di kabupaten Bangkalan sangat kecil, Indek Williamson terendah yaitu ditahun 2007 yaitu sebesar 0,03, sedangkan yang terbesar ditahun 2008 \& 2009 yaitu sebesar 0,15. Dapat diartikan kesenjangan di kabupaten Sampang termasuk dalam kereteria sedang, Indek Williamson dikabupaten Pamekasan yang terendah yaitu ditahun $2005 \& 2006$ sebesar 0,25 dan yang terbesar tahun 2007 sebesar 0,72, kesenjanga dikabupaten Pamekasan dapat dikatakan tinggi karna IW-nya hampir mencapai 1, tapi hanya di tahun 2007 saja, sedangkan untuk kabupaten Sumenep kesenjangan yang terjadi cukup tinggi terlihat dari Indek Williamson yang terendah yaitu sebesar 0,39 dan yang terbesar ditahun 2007 sebesar 0,63, kesenjangan dikabupaten paling tinggi dibandingkan kabupatenkabupaten lain di pulau Madura 
namun masih masuk dalam kriteria sedang.

Kesenjangan pada empat kabupaten dengan nilai rata-rata indeks yang tertinggi sebesar 0,38 , ditahun 2007, yang terendah ditahun 2005 sebesar 0,19. Hasil tersebut menunjukkan bahwa dari tahun 2005 hingga tahun 2009, pembangunan pada empat kabupaten di pulau dengan demikian kondisi perekonomian yang ada di empat kabupaten di pulau Madura berada pada kondisi yang relatif merata, karena Indeks Williamson mendekati nol. Hal ini perlu di waspadai karena kesenjangan yang terjadi masuk dalam kriteria sedang dan nilai kesenjangannya semakin tahun cenderung meningkat.

Madura masuk dalam kriteria sedang,

Tabel 16. Indeks Williamson Empat Kabupaten Di Pulau Madura Atas Dasar Harga Konstan Tahun 2000 ( Jutaan )

\begin{tabular}{llllll}
\hline \multicolumn{1}{c}{ Kabupaten } & 2005 & 2006 & 2007 & 2008 & 2009 \\
\hline Bangkalan & 0,02 & 0,01 & 0,17 & 0,01 & 0,01 \\
Sampang & 0,12 & 0,13 & 0,03 & 0,15 & 0,15 \\
Pamekasan & 0,25 & 0,25 & 0,72 & 0,26 & 0,27 \\
Sumenep & 0,39 & 0,41 & 0,63 & 0,44 & 0,46 \\
\multicolumn{1}{c}{$\quad$ Rata-rata } & 0,19 & 0,20 & 0,38 & 0,21 & 0,22 \\
\hline
\end{tabular}

Sumber : BPS Empat Kabupaten Di Pulau Madura 2011.

\section{PENUTUP}

Secara garis besar berdasarkan hasil analisis data yang telah dilakukan atau dapat diambil kesimpulan yaitu: pertama, Pertumbuhan ekonomi pada masingmasing kabupaten di Pulau Madura secara umum di dominasi oleh sektor pertanian, jasa, pertambangan, bangunan, keuangan dan pengangkutan dimana sektor-sektor tersebut sangat berperan besar dalam memberikan sumbangan terhadap tingkat pertumbuhan Produk Domestik Regional Bruto (PDRB). Pertumbuhan ekonomi pada masingmasing kabupaten di pulau Madura selama kurun waktu 2006 sampai dengan 2009 mengalami fluktuasi dalam pertumbuhan PDBR-nya.

Kedua, Berdasarkan kriteria Tipologi Klassen dapat di ketahui bahwa pada empat kabupaten di pulau Madura termasuk pda klasifikasi daerah "cepat maju dan tumbuh" adalah kabupaten Bangkalan, untuk 
daerah yang termasuk klasifikasi

"daerah maju tapi tertekan" adalah kabupaten Sumenep, untuk "daerah berkembang cepat” adalah kabupaten Pamekasan dan untuk "daerah relatif tertinggal “ adalah kabupaten Sampang.

Ketiga, Sektor unggulan pada masing-masing pada empat kabupaten di pulau Madura sebagian besar masih mengandalkan Pertanian dan Jasa-jasa sebagai sektor yang paling dominan, selain itu sektor Pertambangan, Bangunan, Keuangan dan Pengangkutan juga merupakan sektor unggulan pada masing-masing kabupaten di pulau Madura. Keempat, Kesenjangan atau ketimpangan pendapatan memakai Indeks Williamson menghasilkan nilai ratarata yang berkisar antar 0,19 hingga 0,38. Nilai indek tersebut memberikan indikasi bahwa kesenjangan yang terjadi antar kabupaten yang ada di pulau Madura masuk dalam kriteria sedang dalam kurun waktu 2005 sampai dengan tahun 2009.

Berdasarkan kesimpulan diatas karena pulau Madura juga salah satu bagian dari kawasan yang berperan penting dalam peningkatan pertumbuhan ekonomi Jawa Timur, dalam mengemban tugas tersebut sekaligus mengantisipasi adanya persaingan di era perdagangan bebas diperlukan percepatan pengembangan kawasan yang terfokus pada pengembangan produk sektor unggulan dan non unggulan serta memanfaatkan secara maksimal adanya jembatan Suramadu yang hendaknya diperlukan kerjasama yang baik antara pelaku ekonomi terkait dengan pemerintah daerah. Ada beberapa saran yang dapat diberikan antara lain: Pertama, Pertumbuahan ekonomi suatu daerah tidak bisa lepas dari adanya campur tangan pemerintah, dalam hal ini perintah sebagai fasilitator dan katalisator seharusnya tetap berperan dalam pembangunan fondasi pembangunan ekonomi, seperti pada pengembangan SDM, penelitian dan pengembangan, intensif fiskal, dan kemudahan berinvestasi.

Kedua, Diharapkan pada kebijakan pembangunan yang selanjutnya akan di tempuh oleh pemerintah pada empat kabupaten di pulau Madura dapat meningkatkan pertumbuhan ekonomi, sehingga dengan demikian kabupaten- 
kabupaten yang ada di pula Madura memiliki pertumbuhan ekonomi yang positif dan mampu bersaing dengan kabupaten lainnya di Jawa Timur. Ketiga, Kabupaten-kabupaten yang ada pada pulau Madura termasuk dalam empat klasifikasi Tipologi Klassen, sehingga perlu kiranya pemerintah Propinsi dan Pusat memperhatikan kondisi perekonomian di pulau Madura supaya tarap hidup masyarakat pulau Madura Meningkat terutama kabupaten Sampang, kerena termasuk pada daerah relatif tertinggal, bila dibandingkan dengan kabupatenkabupaten lain di pulau Madura.

Keempat, Meningkatkan sektorsektor ekonomi non unggulan pada empat kabupaten di pulau Madura agar mampu memberdayakan suberdaya manusianya, sehingga nanti dapat menjadi sektor unggulan yang mampu menyerap tenaga kerja lebih banyak. Kelima, Berdasarkan analisis yang telah dilakukan kesenjangan antara empat kabupaten di pulau Madura dari tahun 2005 sampai dengan tahun 2009, kesenjangan yang terjadi di pulau Madura masuk dalam kereteria sedang, dan perlu diperhatikan juga kesenjangan yang terjadi semakin tahun semakin meningkat, hal ini perlu di perhatikan supaya kesenjangan yang terjadi semakin diperkecil lagi.

Pemerintah daerah tingkat I Propinsi Jawa Timur maupun pemerintah daerah pada empat kabupaten di pulau Madura lebih memaksimalkan potensi sektor-sektor perekonomian dengan di oprasikannya jembatan Suramadu yang akan melancarkan mobilitas dalam pengembangan daerah-daerah di pulau Madura agar dapat menumbuhkan atau meningkatkan pendapatan perkapita masing-masing kabupaten di pulau Madura.

\section{DAFTAR PUSTAKA}

Auliyaur Rahman, 2010. Analisa Potensi Ekonomi Sektoral Pada Empat Kabupaten di Pulau Madura. Skripsi Universitas Muhammadiyah Malang, Tidak Dipublikasikan.

Abdul Hakim. 2002. Ekonomi Pembangunan. Ekonisia: Yogyakarta.

Firman Fandi Liswandana. 2010. Analisis Pertumbahan Ekonomi dan Sektor Unggulan Antar Kecamatan di Kabupaten Jember Tahun 2005-2008. Skripsi 
Universitas Muhammadiyah

Malang, Tidak

Dipublikasikan.

Irawan dan Suparmoko. 1987. Ekonomi Pembangunan. Liberty: Yogyakarta.

Lincolin Arsyad. 1997. Ekonomi Pembangunan. STIE YKPN: Yogyakarta.

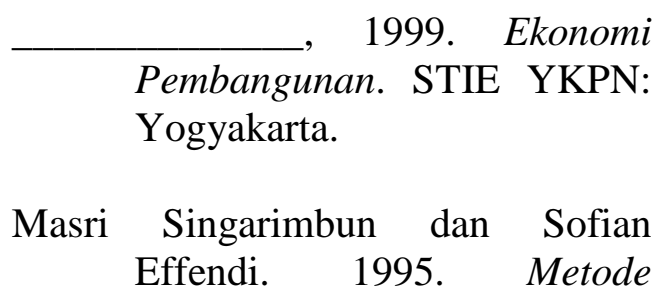

Penelitian Survei. Jakarta: LP3S

Suryana. 2000. Ekonomi Pembangunan Problematika dan Pendekatan. Salemba Empat: Jakarta.

Singgih Santoso dan Fandy Tjiptono. 2000. Riset Pemasaran Konsep dan Aplikasi dengan SPSS. PT. Gramedia: Jakarta.

Todaro, Michael. 2000.

Pembangunan Ekonomi di Dunia Ketiga. Erlangga: Jakarta. 